\title{
Balloon expandable Stent utility for early Secondary Prevention of new Cerebral Ischemic events Caused by Intracranial Atherosclerotic Stenosis. Technical Nuances
}

Gustavo Melo-Guzman ${ }^{1}$, MD, Juan Isidro Ramirez-Rodriguez ${ }^{3}$, MD, Jonathan Ortiz-Rafael ${ }^{6}$, MD, Emma Del Carmen Macias-Cortes ${ }^{2}$, MD, Laura Margarita Sanchez-Garcia ${ }^{4}$, MD, Orlando Villarreal-Barrera ${ }^{5 *}$, MD

${ }^{1}$ Neurologic Endovascular Therapy Department, Mexico Juarez Hospital, Mexico City, Mexico.

${ }^{2}$ Research Department, Mexico Juarez Hospital, Mexico City, Mexico.

3,4,5 Neurologic Endovascular Therapy Fellow, National Autonomous University of Mexico, Mexico Juarez Hospital, Mexico City, Mexico.

${ }^{6}$ Neurosurgery Department, Mexico Juarez Hospital, Mexico City, Mexico.

*Corresponding Author: Orlando Villarreal-Barrera, MD. Neurologic Endovascular Therapy Fellow, National Autonomous University of Mexico, Mexico Juarez Hospital. Instituto Politecnico Nacional Avenue 5160, Magdalena de las Salinas, Gustavo A. Madero Municipality, Mexico City, Mexico, 07760. Email: ovillarreal15@gmail.com

Received date: November 24, 2021; Accepted date: December 13, 2021; Published date: January 03, 2022

Citation: Melo-Guzman G, Ramirez-Rodriguez JI, Ortiz Rafael J, Macias-Cortes EC, Sanchez-Garcia LM, Villarreal-Barrera OE (2022). Balloon expandable Stent utility for early Secondary Prevention of new Cerebral Ischemic events Caused by Intracranial Atherosclerotic Stenosis. Technical Nuances. J. Neuroscience and Neurological Surgery. 11(1); DOI:10.31579/2578-8868/220

Copyrights: (C) 2022 Orlando Villarreal-Barrera, This is an open-access article distributed under the terms of The Creative Commons Attribution License, which permits unrestricted use, distribution, and reproduction in any medium, provided the original author and source are credited.

\section{Abstract}

Objective: Recurrent cerebral ischemic events are estimated to appear in between 12-15\% of symptomatic intracranial atherosclerotic disease (ICAD), regardless of the use of leading pharmacological therapies. Balloon expandable stent (balloon mounted coronary stent) could represent a feasible alternative in this disease's treatment. This study pretends to report the balloon-expandable placement experience in our center.

Materials and Methods: A unicentric retrospective study dated between September 2009 and March 2018 was conducted. Patients previously diagnosed with ICAD and symptomatic stenosis treated with balloon-expandable stent were included. Clinical features, morbidity, mortality, short and long-term evolution, and pre-and post-treatment angiographic features were analyzed, as well as a mean 8 years-period follow-up. Data are presented as means, frequencies, and percentages for categorical variables, and ranks for continuous variables. Statistical analysis was carried by IBM SPSS Statistics Base V22.0 (IBM Corporation, Mexico). A Wilcoxon Signed-rank test statistical analysis was performed. Statistical significance was considered when a p-value lesser than 0.05 was measured for every result.

Results: A total of 6 patients with 7 affected vessels were treated, with an average age of 62.7 years. Affected and treated vessels were located in the Internal Carotid Artery (ICA) segment in 42.9\%, Vertebral Artery (VA) V4 segment in $14.3 \%$, Middle Cerebral Artery (MCA) M1 segment in 28.5\%, and Posterior Cerebral Artery (PCA) P1 segment in $14.3 \%$. The incidence of peri-operatory thrombotic events was $0 \%$. Intracranial hemorrhage presented in $0 \%$ of cases. Recurrent ischemic or thrombotic events were not reported in a $97-$ months mean follow-up. $71.4 \%$ of patients scored $\leq 2$ in the modified Rankin Score (mRS) pre-treatment, in a 90 day and 12 -month followup. $100 \%$ presented a favorable evolution with $\mathrm{mRS} \leq 2$. Restenosis cases were not reported in radiologic control and retreatment was not needed in a 97-month mean follow-up.

Conclusions: This study suggests that balloon-expandable stent therapy with some technical endovascular variants for its navigation and placement could be a safe and effective alternative in the treatment of ICAD as a means of cerebral ischemic event early secondary prevention. We propose to consider not to limit endovascular treatment exclusively to those symptomatic ICAD patients refractory to medical-exclusive treatment, as a means to reduce the risk of presenting a new neurological deficit. Further expanded clinical trials are needed to confirm these findings and the advantage of this kind of stents against other kinds reported in the literature.

Keywords: intracranial atherosclerotic disease; balloon coronary stent; stroke; symptomatic intracranial vascular stenosis 


\section{Introduction}

Intracranial atherosclerotic disease (ICAD) is a frequent cause of cerebral ischemic events in adults, it represents $10 \%$ of ischemic cerebral disease in the United States of America, $14.7 \%$ in Mexico, and 26\% in the Asiatic and Afro-American population. [1-4] In addition to genetic and ethnic components, diabetes mellitus, systemic arterial hypertension, dyslipidemia, and smoking have been associated with a higher incidence of ICAD. [5]

ICAD representative clinical feature is transient ischemic attack, characterized by specific neurologic deficit such as hemiparesis, hemihypoesthesia, dysarthria, or amaurosis fugax. Neurologic deficits are related to anatomical vascular stenosis location, in the following order of appearance: Medial Cerebral Artery (MCA) 44.4\%, Basilar Artery (BA) 18.5\%, Internal Carotid Artery (ICA) $17.2 \%$, Vertebral Artery (VA) $16.1 \%$, Posterior Cerebral Artery (PCA) $2.15 \%$, and vertebrobasilar junction $1.65 \%$. [6]

ICAD neurologic deficit may be the consequence of thrombosis in a stenotic site, single or multiple perforating vessel occlusion by the atheromatous plaque, embolic event, or hypoperfusion. [7] Clinical treatment is based on lifestyle changes and risk-factor control such as diabetes mellitus, systemic arterial hypertension, hypercholesterolemia, and smoking, as well as pharmacological therapy with platelet antiaggregant, and statins. [7] Variability in clinical evolution in ICAD has been described for medical-exclusive treatment against endovascular therapy. [8,9] WASID (Warfarin versus Aspirin for Symptomatic Intracranial Disease) study states that the risk of recurrence of ischemic cerebrovascular disease depends on the stenosis grade, with 19\% recurrence risk in 70-99\% stenosis, and 10\% risk in stenosis lesser than 70\%. (10) SAMPRIS (Stenting versus Aggressive Medical Management for Preventing Recurrent Stroke in Intracranial Stenosis) describes a higher risk of recurrence posterior to endovascular stenosis treatment with non-coronary stent vs. medical-exclusive treatment in one-year follow-up (23.4\% vs $12.0 \%$ ). [11] VISSIT (Vitesse Intracranial Stent Study for Ischemic Stroke Therapy) study reports similar findings to those of SAMPRIS, with $36.2 \%$ recurrence for endovascular treatment with a noncoronary stent versus $15.15 \%$ for medical- exclusive treatment. [11,12]

Durst et al. described lesser morbidity than that previously reported (7.1\%), when using balloon expandable stent in the secondary prevention of ischemic cerebrovascular disease in symptomatic patients with ICAD, despite medical treatment based on double platelet antiaggregant and statins. [13] Similarly, Mayer et al. reported a decreased frequency in ischemic disease with auto-expandable closed-cell stents (Acclino Stent). [14] Some authors consider that the discrepancy between SAMPRIS/VISSIT and other studies might be explained by the lack of experience of neuro interventional specialists in the use of the noncoronary stent (Wingspan Stent), combined with a complex technique that requires exchange of the micro guides in the stent positioning, demanding multiple steps for precise deployment. [13] Despite the best medicalexclusive treatment, a high frequency of ischemic cerebrovascular disease recurrence is reported (12-15.1\%). Posterior to SAMPRIS, other studies have described a lessening in morbidity (2-4.4\%) in symptomatic ICAD with treatment based on stents in selected patients. $[15,16]$ Thus, our study aims to test the safety and efficiency of using balloon expandable stent with some technical deployment variants in early secondary prevention of patients with previous ischemic cerebrovascular disease.

\section{Materials and Methods}

Patient selection: a unicentric retrospective study dated between September 2009 and March 2018 was conducted, previously approved by our institution's local bioethics and research committee (HJM 018/21R institutional protocol). All patients who met the study selection criteria that received treatment in the time period were considered to be included in the study. Confidentiality and anonymity were carried out in conformity to the Declaration of Helsinki.

Data collection was performed in our institute medical registry database and the following variables were considered: sex, comorbidity, localization of stenosis and occlusion grade, risk factors, grade of stenosis reduction posterior to stent placement, pre-and post-treatment modified Rankin Scale (mRS), pharmacological treatment with antiaggregant or statins, peri-operatory adverse events, and imageology control with computed axial tomography and magnetic resonance image. [13-15].

The inclusion criteria were age between 18-85 years old, patients referred from Neurology to Endovascular Neurological Therapy, atherosclerotic disease confirmed by angiography, with stenosis grade of $60-99 \%$ in a major intracranial artery, and previous ischemic cerebrovascular disease related to the anatomical site of vessel stenosis. A single patient was excluded, with V4 segment stenosis treated by stent placement as this patient did not present neurological symptoms associated with this vascular territory. Posterior to the first symptomatic stroke, and confirming by imagenology, all patients were started on statins and antiaggregant in a period of one month, to afterward carry out endovascular treatment by balloon expandable stent. The exclusion criteria were an absence of post-treatment institutional clinical follow-up, a partial or total absence of clinical information relevant to the study in the institutional clinical record, and treatment with at least one type of stent other than balloon expandable. [13,15]

Stenosis grading was performed by the WASID method using angiographic images obtained by digital subtraction: $\left[\left(\begin{array}{ll}1 & -\end{array}\right.\right.$ $\left.\left.\left(\mathrm{D}_{\text {stenosis }} / \mathrm{Dn}_{\text {ormal }}\right)\right)\right] \times 100$, where $\mathrm{D}_{\text {stenosis }}=$ the luminal diameter of the artery at the most severe stenosis site and $\mathrm{D}_{\text {normal }}=$ the diameter of the proximal normal artery. [10]

A series of 7 affected vessels in 6 patients treated with balloon expandable stent was assessed, with presential follow-up initially, and posteriorly by telephone with a mean follow-up of 97-months, in order to evaluate al complications in long-term clinical follow-up from the endovascular treatment to the collecting data date in clinical records.

Processing: Previous informed consent was obtained of all patients. They received dual antiaggregant treatment with acetylsalicylic acid (ASA) $325 \mathrm{mg}$ and clopidogrel $75 \mathrm{mg}$, with a minimal administration period of 7 days previous to endovascular therapy treatment. Platelet reactivity tests were not possible due to technical reasons of the institute. In all cases, endovascular treatment was performed after 14 days from the last symptomatic ischemic vascular event by an experienced neuro interventionalist. [18]

Siemen's monoplane angiography was used. Prior to the procedure, every dispositive was irrigated, and the guide catheter was plugged to a constant saline $0.9 \%$ infusion at an $800 \mathrm{ml} / \mathrm{h}$ rate and the microcatheter was plugged to a $150 \mathrm{ml} / \mathrm{h}$ infusion rate. Intravenous heparin bolus was not administered. Every procedure was performed under general anesthesia, perioperative systolic blood pressure was kept between $90 \mathrm{~mm} \mathrm{Hg}$ to $120 \mathrm{~mm} \mathrm{Hg}$. The right femoral artery was catheterized by a $6 \mathrm{Fr}$ sheath as vascular access of preference. 6 vessel angiographies were executed, and stenosis grade was assessed by the WASID method. A Guider $6 \mathrm{Fr}$ (Stryker) alone or Multipurpose guide catheter 7 Fr (Boston Scientific $\left.{ }^{\circledR}\right)$ together with an Intracranial Support Catheter Navien ${ }^{\circledR}$ (ev3) 6 Fr were used in those cases with tortuosity vessels proximal to the stenosis site. The Tsunami Gold ${ }^{\circledR}$ (Terumo) or Taxus Liberté ${ }^{\circledR}$ and Rebel ${ }^{\circledR}$ (Boston Scientific) Coronary Stent were introduced using a Trascend® microwire, with the support of RoadMap fluoroscopy to reach the stenosis site. Angiographic stent positioning confirmation and a micro guide retraction until the soft tip would be inside the stent were performed. Afterward, balloon angioplasty was performed, inflating the balloon at 1 atmosphere 
below maximal particular nominal of each device, in a lapse of 30 seconds. Angiographic control was performed immediately and after 10 minutes to evaluate residual stenosis and late thrombus formation in the stent placement vascular territory (Figure 1-3). Dual platelet antiaggregant was extended 6-months posterior to the intervention, and afterward, only ASA treatment was kept. [10,13,19]

Clinical evaluation: Clinical parameters assessed in follow-up were new neurological deficit related to the treated vascular territory confirmed by computed axial tomography or magnetic resonance image, ischemic or hemorrhagic cerebrovascular disease, and morbimortality assessed by pre-treatment $\mathrm{mRS}$ and at 90-day and 1-year post-treatment. The recurrence of an ischemic or hemorrhagic cerebrovascular event was also evaluated in a mean follow-up of 97 months. [13]

Radiologic evaluation: Computer tomography angiography control was
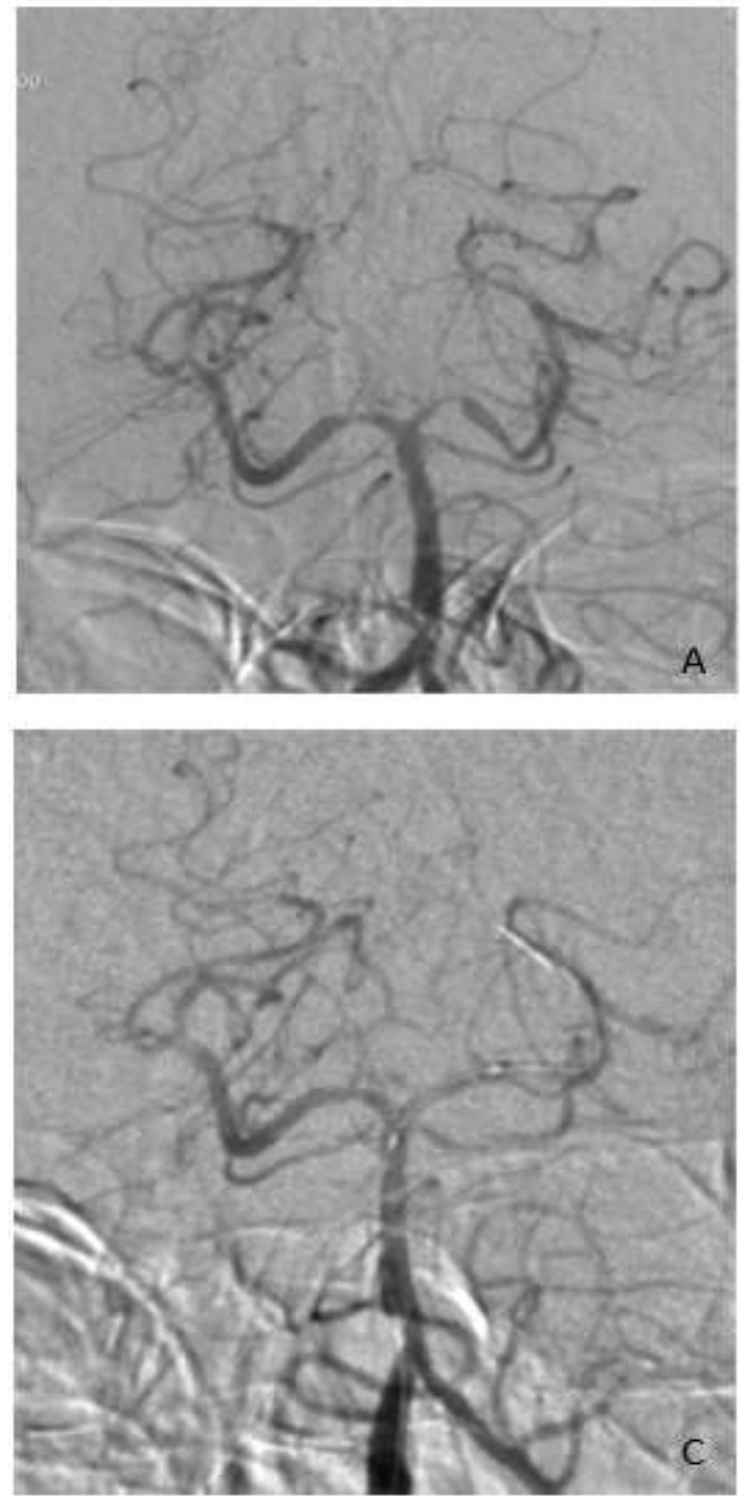

performed 12-months posterior to the intervention, evaluating possible subsequent vascular pathology, late thrombotic events, inadequate stent positioning or migration, and recurrent stenosis, defined as $50 \%$ or higher residual stenosis posterior to stent placement. [13] These findings were reported by two independent neuroradiologists.

Statistical Analysis: Epidemiologic and radiologic data were obtained via institutional medical registry base, in concordance to confidentiality and anonymity standard. Data are presented as means, frequencies, and percentages for categorical variables, and ranks for continuous variables. Statistical analysis was carried by IBM SPSS Statistics Base V22.0 (IBM Corporation, Mexico). A Wilcoxon Signed-rank test statistical analysis was performed. A logistical regression model was used to estimate the association of variables. Statistical significance was considered when a pvalue lesser than 0.05 was measured for every result.
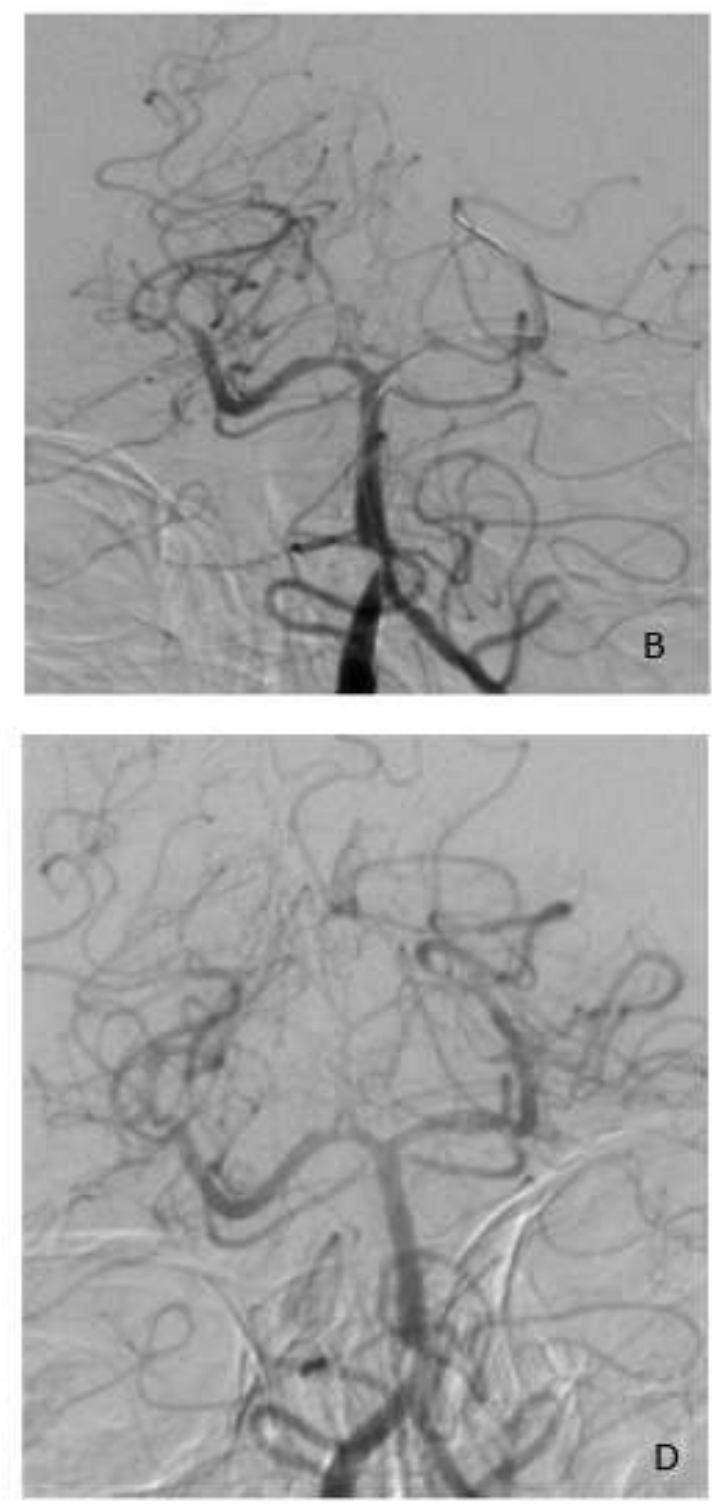

Figure 1: 73-year-old male with previous history of $P C A$ 's vascular territory stroke. A- PCA P1 and proximal basilar artery segment stenosis of $81 \%$ and $40 \%$ respectively. $B$ - Balloon expandable stent placement in PCA P1 segment. C-Stent deployment in stenosis site. D-Angiographic control showing a P1 segment stenosis reduction to $12 \%$ 

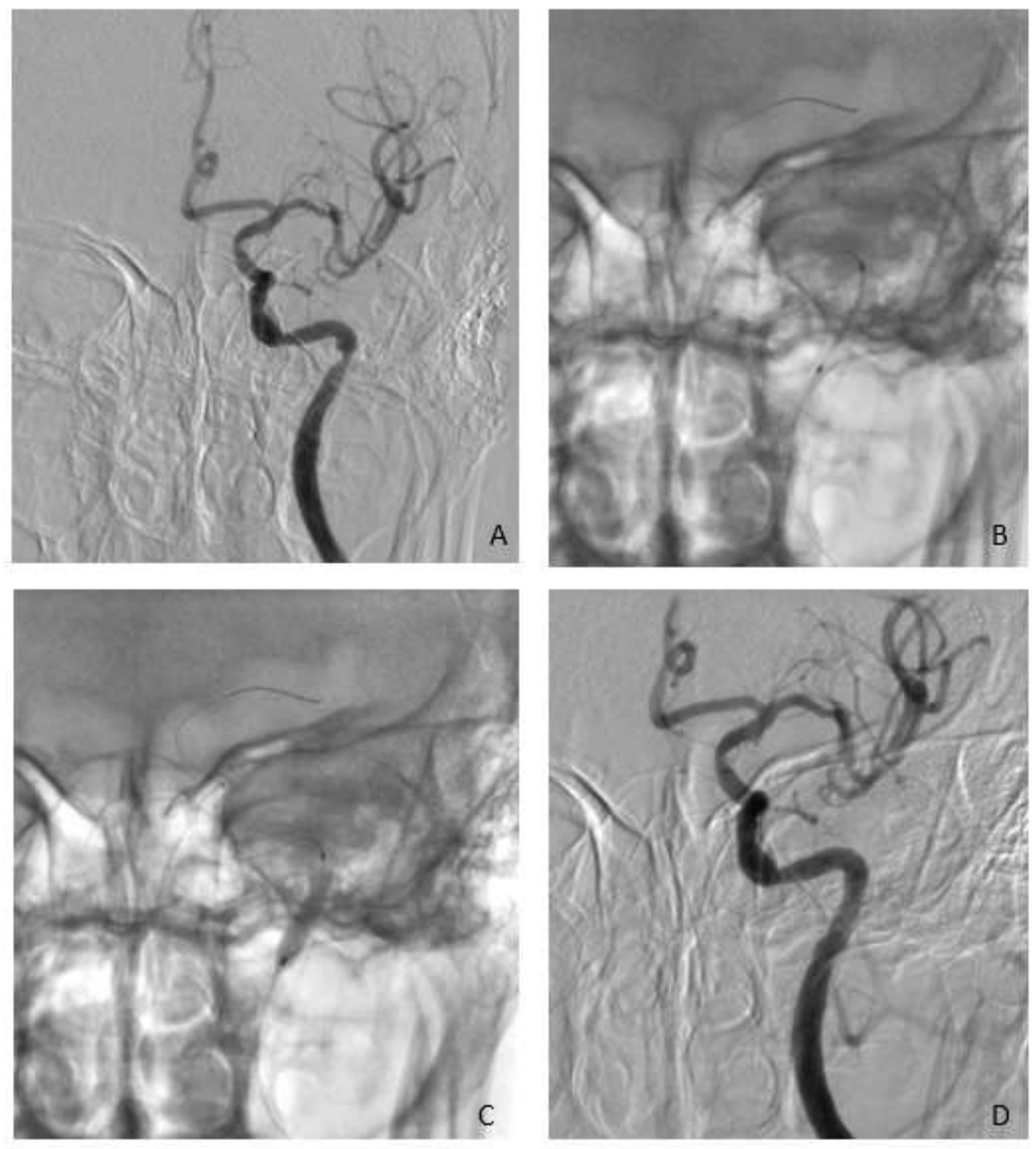

Figure 2: 57-year-old male presented with transient ischemic attack and amaurosis fugax. A- 72\% stenosis in petrous segment of left ICA. BBalloon expandable stent placement in stenosis site. C-Balloon filled with contrast agent. D-Angiographic control posterior to stent placement showing total stenosis resolution. 

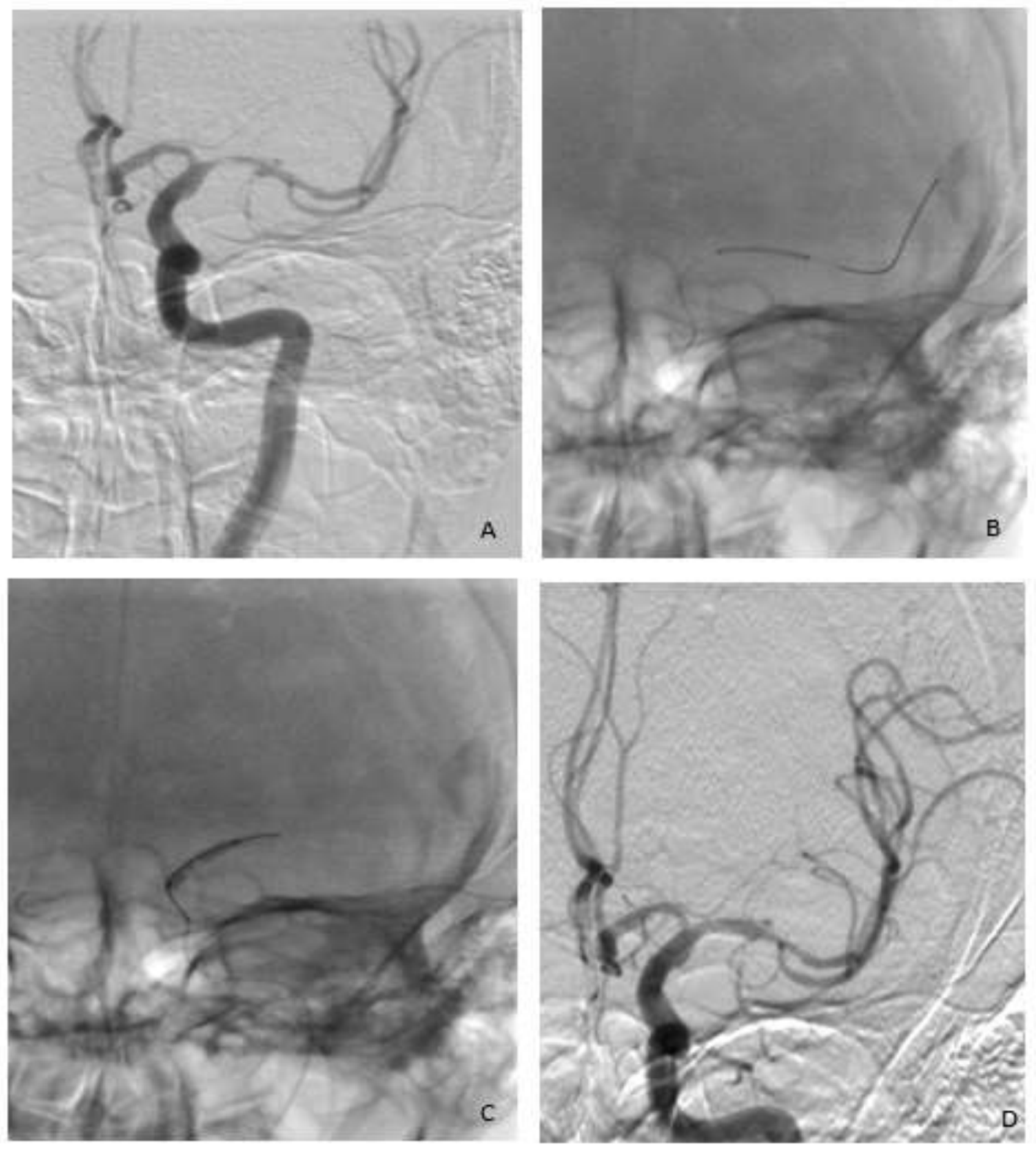

Figure 3: 80-year-old male presented with previous ischemic cerebrovascular disease event comprising the left MCA vascular territory. A- 61\% stenosis of left MCA M1 segment. B-Balloon expandable stent placement in stenosis site. C-Balloon filled with contrast agent over the soft tip of the guide wire positioned in the stenosis site. D- Angiographic control posterior to stent placement showing a stenosis reduction to $20 \%$.

\section{Results}

In a period between September 2009 and March 2018, a total of 6 patients with 7 symptomatic affected vessels were treated using balloon expandable stent. Average age of presentation was 62.7 -years old \pm 11.7 (SD 48-80), and 83\% of cases were in male patients. Clinical presentation was concordant with an ischemic cerebrovascular disease in $71.4 \%$, transient ischemic attack in $14.3 \%$, and vertebrobasilar insufficiency in $14.3 \%$ of all vessels treated. Identified risk factors were systemic arterial hypertension $(66.7 \%)$, diabetes mellitus $(50.0 \%)$, dyslipidemia $(50 \%)$, smoking $(50.0 \%)$ and coronary artery disease (16.7\%). Evidence of previously diagnosed peripheral occlusive vascular disease or atrial fibrillation was not documented. A single patient presented with multiple stenoses requiring treatment in two different vascular territories. Posterior 
circulation was compromised in 2 cases, whereas 5 vessels corresponded to anterior circulation. Affected vessel location was: ICA C2 and C4 segment in $42.9 \%$, MCA M1 segment in $28.5 \%$, VA V4 segment in $14.3 \%$, and PCA P1 segment in $14.3 \%$. (Table 1 )

\begin{tabular}{|c|c|}
\hline \multicolumn{2}{|l|}{ Demographic features $(n=6)$} \\
\hline Age (years), mean (SD), rank & $62.7( \pm 11.7), 48-80$ \\
\hline Male sex $\%$ & 83.3 \\
\hline \multicolumn{2}{|l|}{$\begin{array}{l}\text { Clinical events per vessel treated } \\
(\mathbf{n}=7), \mathbf{n}(\%)\end{array}$} \\
\hline Stroke & $5(71.4)$ \\
\hline Transit ischemic attack & $1(14.8)$ \\
\hline Vertebrobasilar insufficiency & $1(14.8)$ \\
\hline \multicolumn{2}{|l|}{ Risk factors $(n=6)$ n $(\%)$} \\
\hline Hypertension & $4(66.7)$ \\
\hline Smoking & $3(50.0)$ \\
\hline Diabetes & $3(50.0)$ \\
\hline Dyslipidemia & $3(50.0)$ \\
\hline Coronary heart disease & $1(16.7)$ \\
\hline \multicolumn{2}{|l|}{ Stenosis features $(n=7)$} \\
\hline Stenosis grade: median (SD), rank & $79.7( \pm 11.0), 61-93$ \\
\hline \multicolumn{2}{|l|}{ Stenosis grade $\mathrm{n}(\%)$} \\
\hline$<70$ & $1(14.3)$ \\
\hline $70-79 \%$ & $2(28.6)$ \\
\hline $80-89 \%$ & $2(28.6)$ \\
\hline $90-100 \%$ & $2(28.6)$ \\
\hline \multicolumn{2}{|l|}{ Stenosis site $\mathrm{n}(\%)$} \\
\hline Internal Carotid Artery & $3(42.8)$ \\
\hline Middle Cerebral Artery & $2(28.6)$ \\
\hline Posterior Cerebral Artery & $1(14.3)$ \\
\hline Vertebral Artery & $1(14.3)$ \\
\hline
\end{tabular}

Table 1: Demographic, clinical and angiographic features.

Immediate hemorrhagic or thromboembolic in the trans operatory period was not presented (Table 2). Early peri-operatory morbidity/mortality (<30 days) and late peri operatory morbidity-mortality (>30 days) were not reported in any case. One patient presented a thromboembolic event in the MCA M2 segment that required mechanical thrombectomy 9 months posterior of the stent placement to treat PCA P1 segment stenosis, this event was not considered as a late adverse event as it involved a different vascular territory. No new adverse events were reported in a median 97-month follow-up (SD \pm 50.0 ). Risk factors or other features as adverse events predictors were not possible to identify using logistical regression analysis due to small sample size.

Prior to endovascular neurological therapy treatment, $66.7 \%$ of the patients presented with a mRS score of $\leq 2$, in the post-treatment clinical assessments at 90-days and 12-motnhs, a favorable outcome with a mRS score of $\leq 2$ was reported in $100 \%$ of cases (Table 2, Figure 4 ).

\begin{tabular}{|l|l|}
\hline Clinical Evolution $\mathbf{n = 6}(\boldsymbol{\%})$ & \\
\hline Clinical follow-up, median, (SD), rank & 97 months $( \pm 50.0), 1-129$ \\
\hline Thromboembolic events* & $1(16.7)$ \\
Hemorrhagic events & $0(0.0)$ \\
Mortality & $0(0.0)$ \\
\hline Modified Rankin Scale $\mathbf{n}(\%)$ & \\
\hline
\end{tabular}




\begin{tabular}{|c|c|}
\hline \multicolumn{2}{|l|}{ Pretreatment $n=6$} \\
\hline$\leq 2$ & $4(66.7)$ \\
\hline$>2$ & $2(33.3)$ \\
\hline \multicolumn{2}{|l|}{ 90-day follow-up $n=5$} \\
\hline$\leq 2$ & $5(100)$ \\
\hline$>2$ & $0(0)$ \\
\hline \multicolumn{2}{|l|}{ 12-month and beyond follow-up $n=5$} \\
\hline$\leq 2$ & $5(100)$ \\
\hline$>2$ & $0(0)$ \\
\hline Transoperatory adverse events n (\%) & $\mathbf{0}(\mathbf{0})$ \\
\hline \multicolumn{2}{|l|}{$\begin{array}{l}\text { Immediate angiographic findings; mean } \\
\text { (SD), rank }\end{array}$} \\
\hline Posttreatment stenosis & $15.4 \pm 17.9(0-47)$ \\
\hline Stenosis reduction percentage $(\%)$ & $80.9 \% \pm 20.6(49.5-100)$ \\
\hline \multicolumn{2}{|l|}{ 12-month follow-up angiographic findings } \\
\hline Stent occlusion, restenosis, need of retreatment & $0(0)$ \\
\hline
\end{tabular}

* A single case of thrombotic occlusion in MCA M2 segment was reported, not related to the previously treated vascular territory by balloon expandable stent placement (PCA P1 segment)

Table 2: Clinical evolution and angiographic finding

A total of 7 stents were used to treat 7 intracranial vascular stenosis. No technical complications were documented during endovascular approaches. Pre- or post-dilation of the affected vessel in stent liberation was not needed in any case. Radiological follow-up was done in $85.7 \%$ of patients in a period of 12-months or less, posterior to the endovascular treatment. There was no evidence of recurrent stenosis, new thromboembolic event related to the treated vascular territory, inadequate stent positioning or migration, and there was no need for new procedures in previously treated vessels in any case. (Table 2)

Pre-treatment stenosis grade was $79.0 \% \quad(\mathrm{SD} \pm 11.0)$, and $15.4 \%$ $(\mathrm{SD} \pm 17.9)$ in the post-treatment $(\mathrm{p}=0.008)$ and immediate stenosis grade reduction was reported in $80.9 \%$ ( $\mathrm{SD} \pm 20.6)$. (Table 3)

\section{MODIFIED RANKIN SCALE SCORE FOLLOW UP}

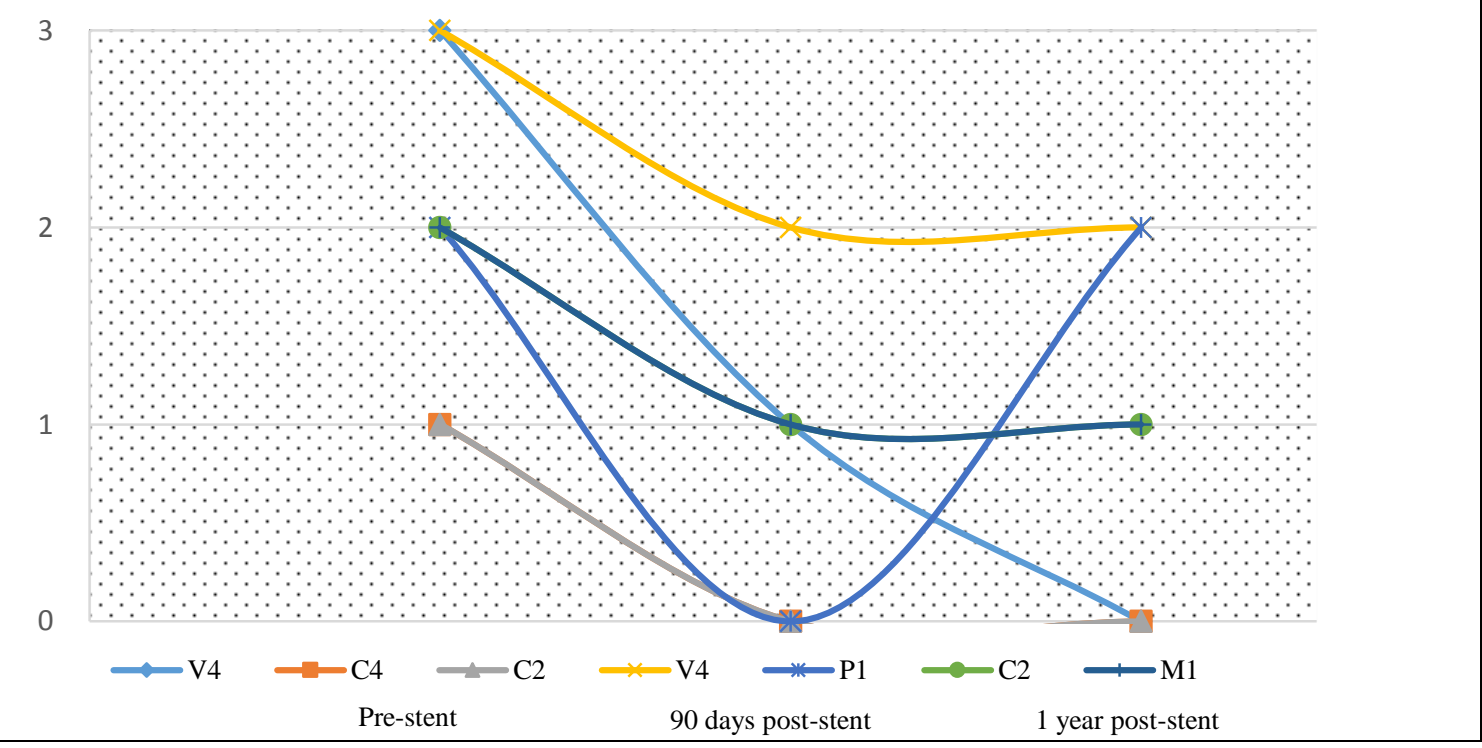




\begin{tabular}{|c|c|c|c|c|c|c|c|c|c|c|c|c|c|c|c|c|c|c|}
\hline Patients & \begin{tabular}{|c|}
$\begin{array}{c}\text { Age } \\
\text { (years) }\end{array}$ \\
\end{tabular} & Sex & Risk factors & $\begin{array}{c}\text { Clinical } \\
\text { presentation }\end{array}$ & $\begin{array}{c}\mathrm{mRS} \\
\text { pretreatment }\end{array}$ & $\begin{array}{c}\text { smR } 90 \\
\text { days post } \\
\text { stent }\end{array}$ & $\begin{array}{c}\text { smR 12 } \\
\text { months } \\
\text { post } \\
\text { stent }\end{array}$ & $\begin{array}{c}\text { Adverse } \\
\text { events }\end{array}$ & Mortality & $\begin{array}{c}\text { Pretreatment } \\
\text { stenosis } \\
(\%)\end{array}$ & $\begin{array}{c}\text { Posttreatment } \\
\text { stenosis } \\
(\%)\end{array}$ & $\begin{array}{c}\text { Stenosis } \\
\text { reduction } \\
(\%)\end{array}$ & \begin{tabular}{|c|} 
Stent \\
occlusion, \\
restenosis, \\
need of \\
retreatment
\end{tabular} & \begin{tabular}{|c|} 
Clinical \\
follow-up \\
(months)
\end{tabular} & $\begin{array}{c}\text { Stenosis } \\
\text { sites }\end{array}$ & $\begin{array}{c}\text { Intraoperative } \\
\text { complications } \\
*\end{array}$ & $\begin{array}{c}\text { Type of } \\
\text { stent } \\
\text { placed }\end{array}$ & $\begin{array}{c}\text { Total } \\
\text { number } \\
\text { of stent } \\
\text { placed }\end{array}$ \\
\hline 1 & 60 & $F$ & $\begin{array}{l}\text { Hypertension } \\
\text { Dyslipidemia } \\
\text { Smoking }\end{array}$ & Isquemic Stroke & 3 & - & - & No & No & 82 & 29 & 64.7 & - & 1 & M1 & No & $\begin{array}{l}\text { Tsuna } \\
\text { mi } \\
\text { Gold } \AA\end{array}$ & 1 \\
\hline 2 & 58 & $\mathrm{M}$ & $\begin{array}{l}\text { Hypertension } \\
\text { Dyslipidemia } \\
\text { Smoking }\end{array}$ & $\begin{array}{l}\text { Transit ischemic } \\
\text { attack }\end{array}$ & 2 & 0 & 0 & No & No & 90 & 0 & 100 & No & 129 & \begin{tabular}{|l|} 
C4 \\
Right
\end{tabular} & No & $\begin{array}{l}\text { Tsuna } \\
\text { mi } \\
\text { Gold } ®\end{array}$ & 1 \\
\hline 2 & & & & Isquemic Stroke & $1 * * *$ & 0 & 0 & No & No & 74 & 0 & 100 & \begin{tabular}{|l|l} 
No \\
\end{tabular} & 129 & \begin{tabular}{|l} 
C4 \\
Left
\end{tabular} & No & $\begin{array}{l}\text { Tsuna } \\
\text { mi } \\
\text { Gold } \AA\end{array}$ & 1 \\
\hline 3 & \begin{tabular}{|l|}
48 \\
\end{tabular} & $\mathrm{M}$ & Diabetes & $\begin{array}{l}\text { Vertebrobasilar } \\
\text { insufficiency }\end{array}$ & 3 & 2 & 2 & No & No & 93 & 47 & 49.5 & No & 54 & V4 & No & $\begin{array}{l}\text { Rebel } \\
(\mathbb{R}\end{array}$ & 1 \\
\hline 4 & \begin{tabular}{|l|}
73 \\
\end{tabular} & $\mathrm{M}$ & $\begin{array}{l}\text { Hypertension } \\
\text { Diabetes }\end{array}$ & Isquemic Stroke & 2 & 0 & 2 & $\begin{array}{l}\text { M1 } \\
\text { acute } \\
\text { occlusi } \\
\text { on ** }\end{array}$ & No & 81 & 12 & 85.2 & \begin{tabular}{|l} 
No \\
\end{tabular} & \begin{tabular}{|l|}
97 \\
\end{tabular} & P1 & No & $\begin{array}{l}\text { Taxus } \\
\text { Liberté } \\
\text { ( }\end{array}$ & 1 \\
\hline 5 & 57 & $\mathrm{M}$ & Smoking & Isquemic Stroke & 2 & 1 & 1 & No & No & 72 & 0 & 100 & No & 97 & $\mathrm{C} 2$ & No & $\begin{array}{l}\text { Tsuna } \\
\text { mi } \\
\text { Gold } \AA\end{array}$ & 1 \\
\hline \multirow[t]{2}{*}{6} & 80 & $\mathrm{M}$ & $\begin{array}{l}\text { Hypertension, } \\
\text { Diabetes, } \\
\text { Dyslipidemia, } \\
\text { Coronary } \\
\text { atery disease, }\end{array}$ & Isquemic Stroke & 2 & 1 & 1 & No & No & 61 & 20 & 67.2 & No & 27 & M1 & No & $\begin{array}{l}\text { Taxus } \\
\text { Liberté } \\
\text { ® }\end{array}$ & 1 \\
\hline & & & & & & & & & & $\begin{array}{c}\text { Mean: } \\
79.0 \% \\
(\mathrm{SD} \pm 11.0)\end{array}$ & $\begin{array}{c}\text { Mean: } \\
15.4 \\
(\mathrm{SD} \pm 17.9)\end{array}$ & $\begin{array}{c}\text { Mean: } \\
80.9 \\
(\mathrm{SD} \pm 20.6)\end{array}$ & & & & & & \\
\hline
\end{tabular}

*Intraoperative complications: inability to place the stent due to anatomical factors, dissections, hemorrhage, thrombosis, hyperperfusion syndrome and ischemic events.

** Mechanical thrombectomy in M1 segment 9 months after endovascular treatment.

*** Patient who presented new neurological symptoms corresponding to a contralateral stenosis of $\mathrm{C} 4$ segment 1 moth after the first endovascular treatment.

Table 3. Summary of all demographic, clinical, and radiological characteristics. 


\section{Discussion}

Findings in this study suggest that ICAD's treatment with balloon expandable stent placement by neurologic endovascular therapy is safe and feasible and presents with a low rate of complications related to the dispositive, ischemic cerebrovascular disease recurrence and mortality. Neurologic endovascular therapy should be reconsidered as a viable treatment alternative in the secondary prevention of ICAD. Even if SAMPRIS and VISSIT studies report a higher incidence of ischemic cerebrovascular disease in 12 months post-treatment in groups treated with medical therapy and stenting versus medical-exclusive treatment, the risk of recurrence in the last group is still high. Inclusion criteria and treatment modality were based upon medical-exclusive treatment presenting a failure rate of $12.0 \%-15.5 \%$ in preventing new strokes in those patients with previous ischemic vascular cerebral disease, compared to $2-4.4 \%$ of recurrence in those that receive combined medical and endovascular treatment. $[11,12,15,16]$ Thus, early endovascular therapy performance can reduce the risk of a subsequent ischemic event in patients receiving medical treatment. $[12,15]$

In this study, posterior to endovascular treatment in 7 vessels, no complications were reported. A single symptomatic VA V4 segment and one in PCA P1 segment were treated and no technical periprocedural adverse events were reported in this subgroup. Compter et al. described in phase II clinical trial of symptomatic stenosis superior to $50 \%$ of the VA treated with stent placement, a morbidity rate of $22.3 \%$ for medicalexclusive treatment and $24.6 \%$ for stent placement. [17] In the morbidity of the stent group, $3.5 \%$ were represented by hemorrhagic cerebrovascular disease, and a mortality of $1.7 \%$ was reported. Despite these findings, the potential benefit from stent endovascular placement in the treatment of symptomatic stenosis of the vertebrobasilar circulation has shown a lesser accumulative risk of presenting cerebrovascular adverse events, compared to treatment in the anterior circulation, which may indicate a long-term significative benefit. [13,17]

In an 8-year follow-up, recurrent thrombotic disease, restenosis, or other adverse events were not reported. This frequency of complications reported in stent-based treatment is low and could be related to drugeluting stents implementation ( 2 of 7 treated vessels), which may perhaps lessen hyperplasia rate, and subsequently, the need for retreatment caused by stenosis or occlusion. [13] Although the use of medicated balloon expandable stents for the treatment of intracranial stenosis has been shown to be a viable alternative, with an apparent decrease in restenosis rates compared to non-medicated stents, there is little data available to justify their use or certain benefit of one type of stent over the other. [20,21]

Some authors attribute an increased morbimortality in groups treated with stent-based therapy to vascular lesions or thromboembolic events triggered by micro guide exchange maneuvers, need of angioplasty prior to stent placement, and in some cases, the necessity of an additional angioplasty. [13] Similarly, previous articles indicate the deployment of the balloon-expandable stent over the rigid segment of the micro guidewire at the site of the stenosis. [19.22]. In our experience, positioning the floppy end of the micro guidewire over the site of the stenosis just before deploying the stent allows it to have a better apposition to the atherosclerotic plaque and vessel walls immediately adjacent to the site of the stenosis, which could theoretically reduce ischemic events due to distal migration of plaque fragments. (Figure 3.C)

The balloon expandable stents utility may be limited for intracranial use in patients with tortuous vascular anatomy. This is due to the feature that its delivery system is relatively rigid; based on this fact we use in selected cases an intracranial support catheter Navien ${ }^{\circledR}$ (Ev3) 6 Fr with 0.072" lumen which we place up to the supraclinoid segment of the internal carotid artery allowing us to navigate the stent without difficulty. The use of this type of catheter and the CAT $5 \AA$ (Stryker), has been previously described as an adjunct for balloon expandable stent navigation in patients with large vessel occlusion associated with intracranial atherosclerotic stenosis. This is associated with higher technical success rates and recanalization but also with higher rates of bleeding and mortality, probably related to multiple previous failed attempts of thrombectomy using stent retriever. [19]

In addition to the technique used to navigate the stent, we consider that insufflating the balloon one atmosphere below the particular nominal value for each stent in order to achieve submaximal angioplasty, theoretically reduces the risk of plaque fragmentation, embolic and hemorrhagic phenomena, and perforators arteries occlusion due to possible plaque mobilization. [23,24] The usefulness of submaximal balloon angioplasty without the use of a stent has been previously described in a meta-analysis by Seyedsaadat et al, where they reported a technical success rate of $93 \%$ with a low incidence of stroke in the first 30 days and at one year of follow-up (3\% and 5\% respectively). [6]

Our study describes a single-step deployment for stents, opposing the multiple phases previously described; the use of submaximal stent angioplasty, and the use of distal access catheter that facilitates navigability, as well as variations in the positioning of the micro guidewire at the time of stent release, all which could be some of the factors that decrease the rate of adverse events.

From the total of patients that received a follow-up longer than 12 months in our study (83.3\%), 100\% showed a favorable clinical evolution (mRS score $0-2$ ).

The limitations of this study include a small sample size that did not allow a logistic regression analysis for the association of risk factors, its retrospective and non-randomized nature, selection bias of anatomically favorable lesions to be treated by neurological endovascular therapy, and lack of a control group verifying the efficacy of this treatment modality.

\section{Conclusions}

At the moment, there are reports of large cohorts describing success in balloon expandable stent usage in patients with recurrent ischemic vascular cerebral disease, secondary to medical exclusive treatment failure. The value in this study relies on its extended period of time follow-up compared to other studies, reporting the feasibility and safety in the employment of these devices with some technical variants for their navigation and placement in early-stage symptomatic patients that received medical exclusive treatment. We propose not to limit endovascular treatment exclusively to those symptomatic ICAD patients refractory to medical-exclusive treatment, as a means to reduce the risk of presenting new neurological deficit.

A bigger sample size clinical trial is needed, with the employment of expandable balloon stents using similar criteria selection in an early stage prior to a new ischemic event, to verify the superiority of this therapeutic modality against medical exclusive treatment or other stent types used in the treatment of ICAD.

\section{References}

1. Gorelick PB, Wong KS, Bae HJ, et al. large artery intracranial occlusive disease. Stroke 2008;39:2396-2399.

2. Sacco RL, Kargman $\mathrm{De}, \mathrm{Gu}$ Q, et al. race-ethnicity and determinants of intracranial atherosclerotic cerebral infarction. Stroke 1995;26:14-20.

3. Wong LKS. Global burden of intracranial atherosclerosis. Int $\mathbf{J}$ Stroke 2006;1:1581-1590

4. Rincon F, Sacco RL, Kranwinkel G, et al. Incidence and risk factors of intracranial atherosclerotic stroke: the Northern Manhattan Stroke Study. Cerebrovasc Dis 2009;28:65e71. 
5. Cantú-Brito C, Majersik JJ, Sánchez BN, Ruano A, Quiñones G, Arzola J, Morgenstern LB. Hospitalized Stroke Surveillance in the Community of Durango, Mexico. The Brain Attack Surveillance in Durango Study. Stroke 2010; 41: 878-884.

6. Seyedsaadat SM, Yolcu YU, Neuhaus A, et al. Submaximal angioplasty in the treatment of patients with symptomatic ICAD: a systematic review and meta-analysis. J NeuroIntervent Surg 2019;0:1-6.

7. Chaturvedi S, Turan TN, Lynn MJ, et al. Risk factor status and vascular events in patients with symptomatic intracranial stenosis. Neurology 2007;69:2063e8.

8. Wareham J, Flood r, Phan K, et al. a systematic review and metaanalysis of observational evidence for the use of bailout selfexpandable stents following failed anterior circulation stroke thrombectomy. J Neurointerv Surg 2019;11:675-682.

9. Cornelissen SA, Andersson T, Holmberg A, et al. intracranial stenting after failure of thrombectomy with the emboTrap ${ }^{\circledR}$ device. Clin Neuroradiol 2019;29:677-683.

10. Chimowitz MI, Lynn MJ, Howlett-Smith H, et al. Comparison of warfarin and aspirin for symptomatic intracranial arterial stenosis. N Engl J Med 2005;352:1305-1316

11. Derdeyn CP, Chimowitz MI, Lynn MJ, et al. Aggressive medical treatment with or without stenting in high-risk patients with intracranial artery stenosis (SAMMPRIS): 15 the final results of a randomised trial. Lancet 2013;383:333-341.

12. Zaidat OO, Fitzsimmons B-F, Woodward BK, et al. effect of a balloon-expandable intracranial stent vs medical therapy on risk of stroke in patients with symptomatic intracranial stenosis: the VissiT randomized clinical Trial Balloon-expandable stent vs medical therapy for intracranial stenosis Balloon-expandable stent vs medical therapy for intracranial stenosis. JAMA 2015;313:1240-1248.

13. Durst CR, Geraghty S, Southerland AM, et al; Stenting of symptomatic intracranial stenosis using ballon mounted coronary stents: a single center experience. J NeuroIntervent Surg 2014; $0: 1-5$
14. Meyer L, Leischner H, Thomalla G, et al. Stenting with Acclino® (flex) for symptomatic intracranial stenosis as secondary stroke prevention, J NeuroIntervent Surg 2020;0:1-5.

15. Gao P, Wang D, Zhao Z, et al. Multicenter prospective trial of stent placement in patients with symptomatic high-grade intracranial stenosis. AJNR Am J Neuroradiol 2016;37:12751280.

16. Miao Z, Song L, Liebeskind Ds, et al. Outcomes of tailored angioplasty and/or stenting for symptomatic intracranial atherosclerosis: a prospective cohort study after SAMMPRIS. J Neurointerv Surg 2015;7:331-335.

17. Compter A, van der Warp HB, Schonewille WJ, et al. Stenting versus medical treatment in patients with symptomatic vertebral artery stenosis: a randomised open label phase 2 trial. Lancet Neurol 2015;14:606-614

18. Alexander MJ, Zauner A, Chaloupka JC, et al. WEAVE trial: results in 152 on-label patients. Stroke 2019;50:889-894.

19. Gross Ba, Desai sM, Walker G, et al. Balloon-mounted stents for acute intracranial large vessel occlusion secondary to presumed atherosclerotic disease: evolution in an era of supple intermediate catheters. J NeuroIntervent Surg 2019;11:975-978.

20. Gupta R, Al-Ali F, Thomas J, et al. Safety, feasibility, and shortterm follow-up of drug-eluting stent placement in the intracranial and extracranial circulation. Stroke 2006;37:2562-2566.

21. Gruber P, Garcia- Esperon C, Berberat J, et al. Neuro Elutax SV drug-eluting balloon versus Wingspan stent system in symptomatic intracranial high-grade stenosis: a single-center experience. J NeuroIntervent Surg 2018;0:1-5.

22. Kang K, Gao F, Mo D, et al. Outcome of endovascular recanalization for intracranial in-stent restenosis. J NeuroIntervent Surg 2020;0:1-6

23. Dumont TM, Sonig A, Mokin M, et al. Submaximal angioplasty for symptomatic intracranial atherosclerosis: a prospective phase I study. J Neurosurg 2016;125:964-971.

24. Karanam LSP, Sharma M, Alurkar A, et al. Balloon angioplasty for intracranial atherosclerotic disease: a multicenter study. J Vasc Interv Neurol 2017;9:29-34.

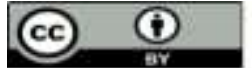

This work is licensed under Creative Commons Attribution 4.0 License

To Submit Your Article Click Here:

Submit Manuscript

DOI: $10.31579 / 2578-8868 / 220$
Ready to submit your research? Choose Auctores and benefit from:

$>$ fast, convenient online submission

$>$ rigorous peer review by experienced research in your field

$>$ rapid publication on acceptance

$>$ authors retain copyrights

$>$ unique DOI for all articles

$>$ immediate, unrestricted online access

At Auctores, research is always in progress.

Learn more https://www.auctoresonline.org/journals/neuroscience-andneurological-surgery 